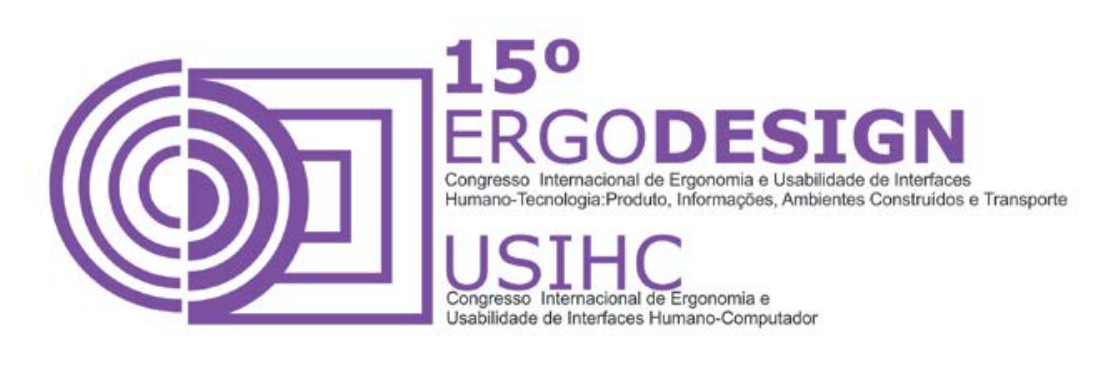

\title{
SIGNOS DE TRÂNSITO PELOS PORTADORES DE DALTONISMO
}

\author{
Frank C. B. Junior (1);
}

OLIVEIRA, Izautino P. (2);

SALES, Lanna (3);

SOUZA, Renata (4)

(1) (2) (3) (4) Centro de Estudos e Sistemas Avançados do Recife

E-mail: frankcbjunior@gmail.com

E-mail: izautinooliveira@gmail.com

E-mail: lannallimas@gmail.com

E-mail: renata.sdsouza@gmail.com

\begin{abstract}
RESUMO
O daltonismo (discromatopsia ou discromopsia) é uma doença que se caracteriza por uma anomalia nos pigmentos das células fotossensoras do olho, resultando assim, no mau funcionamento em relação à detecção de cores, principalmente o verde e o vermelho [1]. A anomalia recebeu esse nome em homenagem ao químico John Dalton, que foi o primeiro cientista a estudar a anomalia de que ele mesmo era portador. A partir de observações etnográficas, entrevistas com os portadores de daltonismo e a aplicação do teste de Ishihara [4], nota-se que a principal inquietação apontada pela pesquisa é a falta de padronização dos semáforos.

Palavras-chaves: Cidade Inteligente, Acessibilidade, Daltonismo.
\end{abstract}

\section{ABSTRACT}

Color blindness (dyschromatopsia or discromopsia) is a disease characterized by an abnormality in the fotossensoras pigments cells of the eye, thereby resulting in a malfunction with respect to detection of colors, preferably red and green [1]. The anomaly was named in honor of the chemist John Dalton, who was the first scientist to study the fault that he was carrying. From ethnographic observations, interviews with people with color blindness and the implementation of the Ishihara test [4], it is noted that the main concern pointed out by the research is the lack of standardization of traffic lights. 


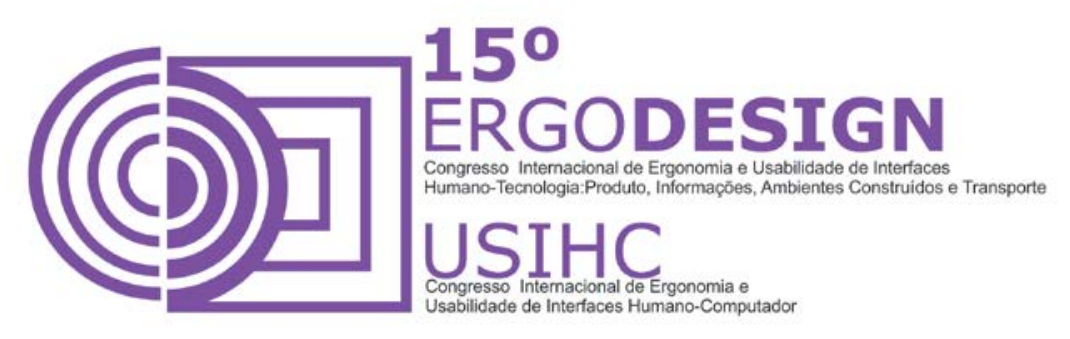

Keywords: Intelligent City, Accessibility, Color Blindness.

\section{INTRODUÇÃO}

No mundo, centenas de milhões de pessoas têm algum problema de visão. O daltonismo é um deles, por exemplo, no Brasil, há 202.768 .562 habitantes onde 14,5\% dessa população apresentam algum tipo de deficiência e 10\% desse grupo algum tipo de daltonismo. $O$ daltonismo é uma anomalia hereditária que afeta um cromossomo sexual $\mathrm{X}$, caracterizando a incapacidade na distinção de algumas cores primárias, ou seja, uma pessoa com daltonismo possui células deficientes resultando na percepção distorcida das cores do espectro cromático, sendo as confusões mais comuns com as cores: verde e vermelho [1].

A alteração da visão acarreta inúmeros constrangimentos aos daltónicos que sentem o peso da discriminação social. No que diz respeito à mobilidade urbana, pessoas com daltonismo podem ter dificuldades de locomoção e identificação de alguns signos de transito, por exemplo, as cores do semáforo. Nesse contexto, é possível identificar a necessidade de cidades mais inteligentes e accessíveis, capazes acolherem os portadores dessa anomalia [2].

Devido ao desacelerado crescimento urbano, as cidades enfrentam uma variedade de riscos, riscos que criam uma urgência em encontrar formas mais inteligentes para gerenciar esses desafios [3] [4]. Nesse contexto, o artigo tem como objetivo, através de pesquisas e entrevistas, identificar problemas enfrentados pelos portadores de daltonismo em seu dia-a-dia, principalmente no trânsito.

\section{PERCEPÇÃO DA COR E O DALTONISMO}

A percepção de cores é dada pelas células da retina chamadas cones. Existem basicamente três tipos de células cones, cada tipo é responsável pela visão de uma das três cores básicas, 0 vermelho, o verde e o azul. As outras cores são, na verdade, a combinação dessas três cores. A percepção é um processamento sensorial que atribui significado a luz recebida de objetos e ambientes, através do uso da memória para converter essas sensações em cor [1] [2]. Logo, para a existência da cor, os dois principais elementos são: o olho e a luz. Um fator importante para a decodificação da cor pelo olho é o comprimento de onda, uma vez que o ser humano possui uma percepção visual particular [5] [6] [7]. O branco, por exemplo, não é considerado cor e sim uma soma de todas as cores juntas, a sensibilidade máxima do espectro se dar nos intervalos de onda que corresponde as cores verde-amarela e azul [5] [6] [8].

O daltonismo é uma deficiência nas células cones, prejudicando a percepção das cores, é um problema que afeta cerca de $10 \%$ da população mundial, sendo a grande maioria do sexo masculino, o problema está geneticamente ligado ao cromossomo $\mathrm{X}$, ocorre com maior frequência entre os homens, que possuem apenas um cromossomo $X$, enquanto mulheres possuem dois cromossomos $X$. Os sintomas mais comuns do daltonismo são problemas para identificar a luminosidade das cores e dificuldade de identificar as cores próximas [9], [10]. A cor 


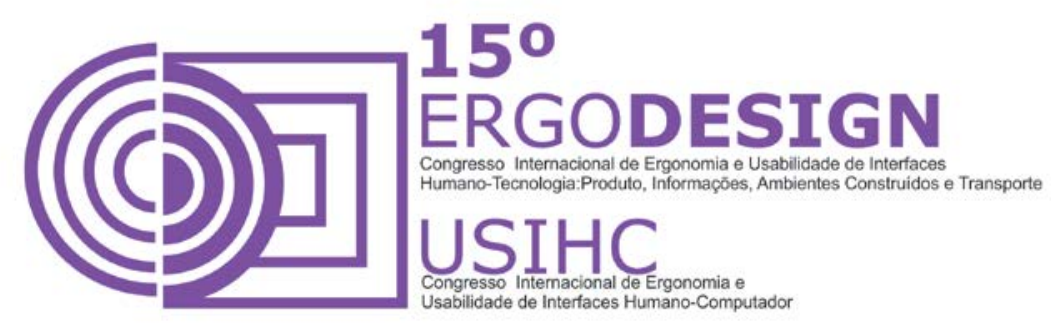

é parte fundamental para a comunicação. A significação da cor pode abranger diversos aspectos na sociedade. É comum usar a cor como referência direta na qualificação de objetos, por exemplo, no trânsito o sinal vermelho significa pare e o verde siga.

Uma das principais formas de identificação de daltonismo é o teste de Ishihara [4], o teste é composto por 32 cartões coloridos com vários círculos que se diferenciam pela tonalidade, saturação e luminosidade em uma mesma prancha [1]. Não há, infelizmente, como corrigir o daltonismo e o portador normalmente aprende a conviver com o problema.

\section{METODOLOGIA}

A metodologia apresentada nesse artigo consiste em uma pesquisa estrutura, cuja produção de dados foi realizada entre dezembro de 2014 e fevereiro de 2015. A população do estudo, definida por conveniência, foram jovens entre 18 e 40 anos portadores de daltonismo. Com total de 13 participantes, recrutados por meio de colegas da faculdade, que convidavam indivíduos com "daltonismo" a participarem do estudo.

Através da pesquisa foram obtidas inicialmente informações socioeconômicas. Em seguida, para identificação objetiva do daltonismo, os voluntários foram submetidos ao teste de Ishihara. A escolha do teste ocorreu por ser um tipo de teste dos mais eficazes para a detecção das deficiências do vermelho e do verde, que são os tipos mais comuns de deficiência [11]. A versão com 24 pranchas, usada neste estudo, as pranchas utilizadas para distinguir os defeitos do eixo vermelho-verde entre si. Foram incluídos nessa pesquisa indivíduos que falharam na identificação de pelo menos oito das 24 pranchas, confirmando a presença da anomalia.

O modo de apresentar o tema aos participantes, sem tempo cronometrado para respostas e diálogos, permitiu um melhor aproveitamento da entrevista. Após a coleta, todo material de estudo foi organizado e analisado. A pesquisa revelou que os daltônicos enfrentam problemas com a falta de padrão de semáforos e placas de uma cidade para outra. Para eles, o contraste é essencial para melhorar a visibilidade no trânsito. Foi detectado também que os semáforos em LED atrapalham a identificação da cor por emitir excesso de luminosidade.

\section{CONSIDERAÇÕES FINAIS}

Esta pesquisa procurou analisar as dificuldades de pessoas com daltonismo em relação ao transito. A partir dos dados apresentados, a pesquisa mostrou que existe uma parcela significativa da população portadora de daltonismo. Foram mencionadas também pelos entrevistados que embora as pessoas daltônicas desenvolvam espontaneamente mecanismos de enfrentamento para as dificuldades do dia-a-dia, várias iniciativas parecem caber ao poder público, por exemplo, a falta de padronização no que diz respeito aos semáforos.

Assim é importante salientar a importância de uma solução no que diz respeito a Cidades Inteligentes para a identificação de signos do transito baseado em cores de forma mais acessível e adaptativa para pessoas que apresentam a anomalia. 


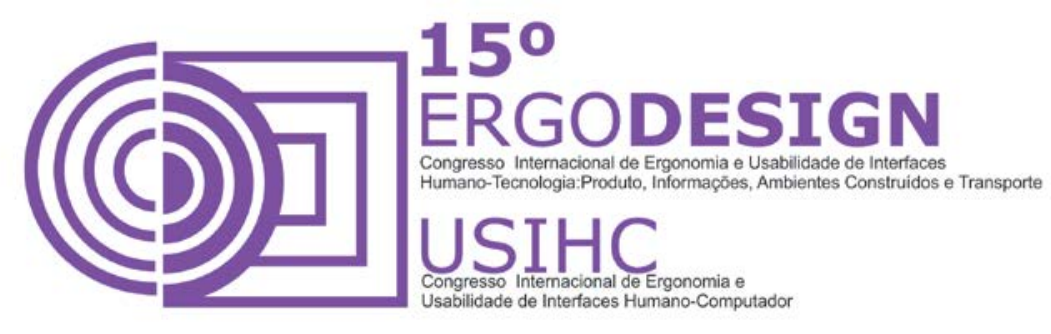

\section{REFERÊNCIAS BIBLIOGRÁFICAS}

[1] T. De Curitiba, Representação Gráfica de Mapas para Daltônicos: Um Estudo de Caso dos, 2013.

[2] M. Naphade, G. Banavar, C. Harrison, J. Paraszczak, and R. Morris, Smarter cities and their innovation challenges, Computer (Long. Beach. Calif)., vol. 44, pp. 32-39, 2011.

[3] T. Nam and T. a. Pardo, Conceptualizing smart city with dimensions of technology, people, and institutions, Proc. 12th Annu. Int. Digit. Gov. Res. Conf. Digit. Gov. Innov. Challenging Times - dg.o '11, p. 282, 2011.

[4] Teste de Ishihara. Disponível em < http://www.ibrau.com.br/ishihara.htm >

[5] lida,Itiro. Ergonomia: Projeto e Produção. $2^{a}$. Edição revista e ampliada. Editora Edgard Blucher. São Paulo, 2005

[6] Pedrosa, I. Da cor à cor Inexistente. 10 ed. Senac, Rio de Janeiro, 2009

[7] Asato, André; Gonçalves, Rafael. Visocor: Sistema de Acessibilidade Visual. Instituto de Matemática e Estatística. Universidade de São Paulo, 2009.

[8] Farina, Modesto; Rodrigues, Maria Clotilde; Filho, Heliodoro. Psicodinâmica das Cores em Comunicação. 5a. Edição. Edgard Blucher. São Paulo, 2006

[9] Neiva, Miguel. Sistema de Identificação de Cor para Daltônicos: Código Monocromático. Dissertação de Mestrado. Universidade do Minho, Portugal, 2008

[10] The New York Times - Color blindness is the inability to see certain colors in the usual way. Disponível em: http://www.nytimes.com/health/quides/disease/color-blindness/overview.html

[11] F. D. E. Tecnologia, DISCROMATOPSIA CONGÊNITA NA PERCEPÇÃO, 2009. 